\title{
The predominant form of non-toxic goiter in Greece is now autoimmune thyroiditis
}

\author{
Anthony G Doufas ${ }^{1}$, George Mastorakos ${ }^{1}$, Sofia Chatziioannou ${ }^{1}$, Sofia Tseleni-Balafouta ${ }^{2}$, Gregory Piperingos ${ }^{1,3}$, \\ Michael A Boukis ${ }^{1}$, Emily Mantzos ${ }^{1}$, Constantine S Caraiskos ${ }^{1}$, John Mantzos ${ }^{1}$, Maria Alevizaki ${ }^{1,3}$ and \\ Demetrios A Koutras ${ }^{1,3}$ \\ ${ }^{1}$ Endocrine Unit, Evgenidion Hospital, ${ }^{2}$ Department of Clinical Therapeutics, Pathology Department and ${ }^{3}$ Alexandra Hospital, Athens University, \\ Athens, Greece \\ (Correspondence should be addressed to A G Doufas, 22, Moudanion Street, 18451 Nikea, Piraeus, Greece)
}

\begin{abstract}
Endemic non-toxic goiter (NTG) in Greece has been attributed primarily to iodine deficiency. Thirty years ago about $60 \%$ of the prepubertal boys and girls examined in endemic goiter regions presented with NTG and among them thyroid autoimmunity was rarely detected. Although iodine supplementation has corrected this deficiency during the past 30 years, new cases of NTG still appear. To evaluate the prevalence and type of NTG and the effect of iodine supplementation on them in Greece at present, we performed two cross-sectional clinical studies and a retrospective pathology one: (i) thyroid gland volume and urinary iodine excretion (UIE) were assessed in a representative sample of 1213 schoolchildren from previously endemic and non-endemic regions; (ii) serum thyroxine, tri-iodothyronine, TSH, thyroid autoantibodies (AAB) (anti-thyroid peroxidase and anti-thyroglobulin antibodies) and UIE (in 60 patients) were measured in 300 consecutive patients with NTG from Athens and Heraklion; and (iii) we compared the prevalence of autoimmunity among fine needle aspiration smears of benign thyroid pathologies performed by the same pathologist between 1985 and 1986 (975 cases) and between 1994 and 1995 (2702 cases). We found that $12.5 \%$ of the schoolchildren examined in regions with a previous history of endemic goiter had NTG, whereas this percentage was only $1.7 \%$ in areas without such a history. In Athens (61.6\%) and Heraklion (58.5\%) a substantial number of NTG patients were $\mathrm{AAB}$ positive and biochemically hypothyroid. UIE in Athens did not differ between patients with autoimmune goiter (ATG) and simple goiter. The prevalence of autoimmune stigmata in pathology smears has increased from 5.94\% (years 1985-1986) to 13.91\% (years 1994-1995) $(P<0.05)$. We conclude that: (i) the persistence of endemic goiter in regional foci despite iodine deficiency correction suggests a possible role for a naturally occurring goitrogen; (ii) ATG is the predominant form of NTG in Greece nowadays; and (iii) the five-fold decrease in the prevalence of NTG during the past 30 years followed by the increase of ATG may support the relative character of the latter.
\end{abstract}

European Journal of Endocrinology 140 505-511

\section{Introduction}

In Greece, 30 years ago the large majority of non-toxic goiter (NTG) was endemic and it was due to iodine deficiency $(1,2)$. At that time, the mean prevalence of NTG among prepubertal boys and girls from endemic goiter areas was about $60 \%(1)$, while the prevalence of thyroid autoantibodies (AAB), as estimated by the complement-fixation test, among adult patients with NTG was about $12 \%$ (3). Although iodine-deficient areas still exist in isolated mountainous regions of Northern Greece, iodine deficiency has been reduced to a great extent during the past 30 years. Dietary iodine intake in Athens has almost quadrupled, reaching the optimum level of about $200 \mu \mathrm{g}$ iodine/day (4). The urinary iodine excretion (UIE) in Athens was $45 \mu \mathrm{g} /$ day in 1964 (3), $95 \mu \mathrm{g} / \mathrm{g}$ creatinine ( $\mathrm{Cr})$ in 1980 (5), and $208 \mu \mathrm{g} / \mathrm{g} \mathrm{Cr}$ in 1991 (6). However, new cases of NTG still appear. It has been suggested that environmental and/or genetic factors may be involved in the pathogenesis of this goiter (7). On the other hand, it is possible that this may be due to the iodine supplementation itself, since increased iodine intake has been implicated in triggering thyroid autoimmunity $(8-10)$.

To assess the prevalence of NTG in Greece today after iodine supplementation, we evaluated the presence of goiter and we assessed the UIE in 1213 schoolchildren from previously endemic and non-endemic regions. Subsequently, to evaluate the contribution of autoimmunity in goiter formation in Greece at present, we examined the autoimmune profile of 300 consecutive patients with NTG from two cities (Athens and 
Heraklion) and we measured the UIE in 60 of these patients. The term 'autoimmune goiter' (ATG) denotes any NTG associated with positive serum AAB.

Finally, the evolution of thyroid autoimmunity in Greece was examined retrospectively by evaluating the prevalence of autoimmunity-related pathology stigmata in thyroid fine needle aspiration (FNA) specimens over the past 10 years.

\section{Subjects and methods}

\section{Schoolchildren study}

One thousand two hundred and thirteen schoolchildren (1213) (aged 9-11 years) from 17 different regions in Greece with (497 from 11 regions) or without (716 from 6 regions) a past history of endemic goiter underwent physical examination (Table 1). All children at the studied ages from each region were included in the survey, and they and their parents were well informed and aware of the purpose of this study. The regions with ( 11 regions) and without ( 6 regions) a past history of endemic goiter from which schoolchildren were examined have been selected based on studies performed 30 years ago in the same geographical areas $(1-3)$. Thyroid gland volume was assessed clinically and assigned into one of five stages according to the PAHO criteria (Stage 0: no goiter; Stage Ia: goiter detectable only by palpation and not visible when the neck is fully extended; Stage Ib: goiter palpable and visible only when the neck is fully extended, and including nodular glands even if not goitrous; Stage II: goiter visible with the neck in normal position, palpation not needed for diagnosis; Stage III: very large goiter that can be recognized at a considerable distance) $(11,12)$. To transform the goiter Stage into a semi-quantitative estimate each Stage was expressed as an estimated weight (Stage Ia: 35-45 g; Stage Ib: 45-65 g; Stage II: 65-100 g; Stage III: $>100$ g). Any thyroid enlargement assessed by palpation to be $40 \mathrm{~g}$ or more (Stages Ia-III) was considered to be a goiter. Glands just palpable (Stages 0 and Ia) were considered normal. A urine sample for iodine and $\mathrm{Cr}$ measurements was also obtained.

\section{NTG study}

Three hundred consecutive patients with NTG were examined prospectively at two referral thyroid units. All patients gave informed consent for the study. Two hundred and six patients were referred to a unit located in Athens, whereas 94 were referred to the Heraklion unit in Crete. Of the former 206 patients, 191 were women aged 9-83 years (mean \pm s.D. 36.3 \pm 13.4 ), and 15 were men aged $13-45$ years $(27.0 \pm 9.2)$. From the 94 patients examined in Heraklion, 78 were women aged 17-66 years $(36.2 \pm 12.5)$, and 16 were men aged 13-55 years $(31.7 \pm 12.6)$. The dietary iodine intake was roughly evaluated from the number of iodine-rich meals (chicken and/or fish) per week (13). Family history of thyroid diseases was also recorded. All patients underwent physical examination. None of the consecutive patients included in this study had clinical signs and/or symptoms of overt hypothyroidism. Thyroid gland size was assessed clinically, as described

Table 1 UIE (mean \pm S.D), goiter prevalence and PAHO Stages from the schoolchildren study, in regions with and without a past history of endemic goiter in Greece.

\begin{tabular}{|c|c|c|c|c|c|}
\hline \multirow{2}{*}{$\begin{array}{l}\text { Region of Greece } \\
(17 / n=1213)\end{array}$} & \multirow{2}{*}{$\begin{array}{c}\text { UIE } \\
(\mu \mathrm{g} \mathrm{I} / \mathrm{g} \mathrm{Cr})\end{array}$} & \multirow{2}{*}{$\begin{array}{c}\text { Goiter } \\
(\%)\end{array}$} & \multicolumn{3}{|c|}{$\begin{array}{c}\text { PAHO Stages } \\
(\%)\end{array}$} \\
\hline & & & la & $\mathrm{lb}$ & II \\
\hline \multicolumn{6}{|l|}{ Past history $(11 / n=497)$} \\
\hline Athamanio-loannina (43) & $45 \pm 59$ & 14.0 & 72.1 & 25.6 & 2.3 \\
\hline Boulgarelli-Arta (11) & $63 \pm 59$ & 0 & - & - & - \\
\hline Agnanti-Fthiotida (11) & $114 \pm 99$ & 0 & - & _ & _- \\
\hline Fourna-Evritania (19) & $72 \pm 64$ & 5.0 & 84.2 & 15.8 & - \\
\hline Dafni-Evritania (42) & $44 \pm 48$ & 4.7 & 88.1 & 11.9 & - \\
\hline Gra-Lygia-Lasithi (67) & $167 \pm 163$ & 25.4 & 56.8 & 37.3 & 5.9 \\
\hline Kavousi-Lasithi (8) & $128 \pm 111$ & 0 & - & - & - \\
\hline Palaiokastro-Lasithi (42) & $111 \pm 103$ & 0 & - & - & - \\
\hline Ano \& Kato Zaro-Lasithi (70) & $161 \pm 144$ & 21.0 & 61.4 & 30.0 & 8.6 \\
\hline Asminio-Evoia (16) & $164 \pm 111$ & 0 & - & - & - \\
\hline Istiaia-Evoia (168) & $132 \pm 133$ & 13.0 & 54.1 & 30.5 & 15.4 \\
\hline \multicolumn{6}{|l|}{ Past history $(6 / n=716)$} \\
\hline Agios Konstantinos-Fthiotida (91) & $175 \pm 155$ & 0 & - & - & - \\
\hline Kamena Vourla-Fthiotida (73) & $175 \pm 195$ & 2.8 & 86.4 & 12.3 & 1.3 \\
\hline Heraklion-Crete (148) & $176 \pm 157$ & 6.7 & 85.1 & 14.9 & - \\
\hline Siros-Cyclades (69) & $191 \pm 149$ & 0 & - & - & _- \\
\hline Agia Paraskevi-Athens (205) & $191 \pm 158$ & 0 & _- & - & - \\
\hline Ampelokipi-Athens (130) & $95 \pm 104$ & 0 & - & - & - \\
\hline
\end{tabular}


Table 2 Clinical and biological characteristics (mean \pm S.E.M.) of the 300 patients with NTG from Athens and Heraklion.

\begin{tabular}{|c|c|c|c|c|}
\hline & \multicolumn{2}{|c|}{$\begin{array}{l}\text { ATHENS } \\
(n=206)\end{array}$} & \multicolumn{2}{|c|}{$\begin{array}{l}\text { HERAKLION } \\
\quad(n=94)\end{array}$} \\
\hline & $\begin{array}{c}\text { ATG } \\
(n=127)\end{array}$ & $\begin{array}{l}\text { Simple goiter } \\
\quad(n=79)\end{array}$ & $\begin{array}{c}\text { ATG } \\
(n=55)\end{array}$ & $\begin{array}{c}\text { Simple goiter } \\
n=39\end{array}$ \\
\hline Age (years) & $35.7 \pm 1.3$ & $35.0 \pm 1.4$ & $37.1 \pm 1.7$ & $33.0 \pm 1.9$ \\
\hline $\operatorname{Sex}(F / M)$ & $123 / 4$ & $68 / 11$ & $44 / 11$ & $34 / 5$ \\
\hline Goiter weight (g) & $48.4 \pm 1.17^{\mathrm{a}}$ & $44.7 \pm 0.82$ & $49.4 \pm 2.21$ & $44.5 \pm 1.02$ \\
\hline Goiter consistency $(\mathrm{D} / \mathrm{N})^{*}$ & $71 / 56$ & $57 / 22$ & $27 / 28$ & $23 / 16$ \\
\hline $\mathrm{T}_{4}(\mathrm{nmol} / \mathrm{l})$ & $95.49 \pm 3.08$ & $102.83 \pm 3.08^{g}$ & $94.98 \pm 6.04^{d}$ & $120.98 \pm 10.94$ \\
\hline $\mathrm{T}_{3}(\mathrm{nmol} / \mathrm{l})$ & $1.66 \pm 0.07$ & $1.98 \pm 0.24$ & $2.35 \pm 0.70$ & $2.01 \pm 0.16$ \\
\hline TSH (mU/l) & $16.6 \pm 3.48^{b}$ & $1.49 \pm 0.17$ & $11.2 \pm 2.14^{c}$ & $1.55 \pm 0.21$ \\
\hline $\mathrm{RT}_{3} \mathrm{U}$ & $0.29 \pm 0.04$ & $0.29 \pm 0.08$ & $0.24 \pm 0.03^{\mathrm{e}}$ & $0.30 \pm 0.06$ \\
\hline TPOAb (AU/ml) & $2283 \pm 342$ & $13.59 \pm 3.20$ & $2802 \pm 574$ & $40.27 \pm 7.69$ \\
\hline $\operatorname{TgAb}(\mathrm{U} / \mathrm{ml})$ & $606.54 \pm 208.22$ & $62.36 \pm 50.64$ & $390.15 \pm 84.34$ & $21.93 \pm 4.03$ \\
\hline $\mathrm{I} / \mathrm{Cr}(\mu \mathrm{g} / \mathrm{g})$ & $222.9 \pm 21.19(28)$ & $204.7 \pm 21.65(24)$ & $277.4 \pm 71.00(5)$ & $215.0 \pm 4.16$ \\
\hline Chicken/fish consumption (meals/week) & $2.15 \pm 0.10$ & $2.26 \pm 0.16$ & $3.20 \pm 0.26^{f}$ & $2.24 \pm 0.20$ \\
\hline Family history $(\mathrm{Y} / \mathrm{N})$ & $25 / 101(19.6 \%)$ & $24 / 55(30.4 \%)$ & $7 / 21(25 \%)$ & $5 / 20(20 \%)$ \\
\hline
\end{tabular}

a Significantly different from simple goiter in Athens $(P<0.05)$.

${ }^{b}$ Significantly different from simple goiter in Athens $(P<0.001)$.

${ }^{\mathrm{c}}$ Significantly different from simple goiter in Heraklion $(P<0.001)$.

d Significantly different from simple goiter in Heraklion $(P<0.05)$.

e Significantly different from simple goiter in Heraklion $(P<0.05)$.

${ }^{f}$ Significantly different from simple goiter in Heraklion $(P<0.01)$.

g Significantly different from simple goiter in Heraklion $(P<0.05)$.

${ }^{*} \mathrm{D} / \mathrm{N}=$ diffuse/nodular

above, by two clinicians (DAK in Athens and M A B in Heraklion) who had a high degree of concordance, as proven in previous epidemiological studies $(6,8)$. However, it should be noted that, in general, clinical assessment of thyroid gland size by palpation by independent observers can be misleading, as has been previously suggested (14). A distinction was also made between diffuse and non-toxic multinodular goiters. Biochemical evaluation included measurements of serum thyroxine $\left(\mathrm{T}_{4}\right)$, tri-iodothyronine $\left(\mathrm{T}_{3}\right)$, thyroidstimulating hormone (TSH), $\mathrm{T}_{3}$ resin uptake $\left(\mathrm{RT}_{3} \mathrm{U}\right)$, and $\mathrm{AAB}$ (anti-thyroid peroxidase antibodies (TPOAb) and anti-thyroglobulin antibodies ( $\mathrm{Tg} A b)$ ). In 60 patients UIE and $\mathrm{Cr}$ were also estimated.

Based on the presence or absence of serum AAB, patients with NTG were classified, respectively, as having either an ATG or a simple goiter (Table 2).

\section{FNA study}

Four thousand two hundred and fifty (4250) thyroid biopsies obtained by FNA from patients with nodular NTG (multinodular or solitary thyroid nodules) from Athens were studied retrospectively (1250 biopsies taken between the years 1985 and 1986, and 3000 between 1994 and 1995). All patients were clinically euthyroid and the two study groups had similar ages and female/male ratio (Table 3). FNA specimens were taken only from the thyroid nodules and the biopsy technique used in the two study periods was exactly the same and was performed by the same pathologist (S T-B). The two series of specimens were also examined by the same pathologist (S T-B) and compared on the basis of the prevalence of pathology stigmata of autoimmune lymphocytic thyroiditis. Diagnosis was considered positive when the following minimal histopathological criteria were met: (i) diffuse infiltration of the smear by numerous lymphoid cells including small lymphocytes and centroblasts, and scattered plasma cells. In order to minimize the possibility that a non-specific lymphocytic thyroiditis or a peritumoral lymphocytic infiltration was diagnosed as Hashimoto's thyroiditis we have excluded cases with focal lymphocytic infiltration alone or scattered lymphocytes (15). (ii) Presence of follicle cells in monolayered sheets and follicular formations with moderate anisokaryosis, without severe atypia. Cases with suspicion of neoplasia were excluded.

Table 3 Results of the retrospective FNA study from the two study periods.

\begin{tabular}{lcc}
\hline & $\begin{array}{c}\mathbf{1 9 8 5 - 8 6} \\
(n=1250)\end{array}$ & $\begin{array}{c}\mathbf{1 9 9 4 - 9 5} \\
(n=3000)\end{array}$ \\
\hline Age (years \pm s.D. $)$ & $48.4 \pm 9.3$ & $43.0 \pm 12.2$ \\
Sex (F/M) & $1147 / 103$ & $2724 / 276$ \\
Thyroid cancer & 275 & 298 \\
Benign goiters & 975 & 2702 \\
Hashimoto's & $58(5.94 \%)^{\star}$ & $376(13.91 \%)$ \\
Simple & 917 & 2326 \\
\hline
\end{tabular}

* Significantly different from the prevalence of Hashimoto's goiter in the 1994-95 benign thyroid specimen series $(P<0.05)$. 
More specifically, smears were generally cellular with scanty colloid. Most frequent pathology findings included Askanazy cells in sheets with moderate anisokaryosis and atypia. Blue cytoplasmic fragments in the background, histiocytes (often clustered in association with lymphocytes), epithelioid cells with elongated nuclei and sparse small multinucleate giant cells were also found.

\section{Assays}

$\mathrm{T}_{4}$ and $\mathrm{T}_{3}$ concentrations were measured by RIA (AMERLEX-M T4, AMERLEX-M T3 RIA kits). The detection limits of the $T_{4}$ and $T_{3}$ assays were $4.0 \mathrm{nmol} / \mathrm{l}$ and $0.15 \mathrm{nmol} / \mathrm{l}$, whereas the normal ranges were $61.8-164.7 \mathrm{nmol} / \mathrm{l}$ and $0.8-2.7 \mathrm{nmol} / \mathrm{l}$ respectively. TSH concentration was measured by a onestep IRMA technique (hsTSH Coated Tube Assay, Johnson \& Johnson Clinical Diagnostics). The detection limit of the TSH assay was $0.03 \mathrm{mU} / \mathrm{l}$, and the normal reference range was $0.32-4.0 \mathrm{mU} / \mathrm{l}$. $\mathrm{RT}_{3} \mathrm{U}$ was also measured and the normal range was between 0.25 and $0.35(25-35 \%)$.

The level of TPOAb was measured with an RIA kit (ABTPO, Sorin Biomedica). The assay sensitivity was below 4 arbitrary units $/ \mathrm{ml}(\mathrm{AU} / \mathrm{ml})$, and the normal range of $\mathrm{TPOAb}$ was below $10 \mathrm{AU} / \mathrm{ml}$. The estimation of $\mathrm{TgAb}$ level was made by an IRMA technique (AB-HTGK-3, Sorin Biomedica). The assay sensitivity was below $5 \mathrm{U} / \mathrm{ml}$, and the normal range for this $\mathrm{TgAb}$ was below $100 \mathrm{U} / \mathrm{ml}$.

Urinary iodine was estimated by the manual method of Benotti \& Benotti (16). The values were calculated as $\mu \mathrm{g}$ iodine per $\mathrm{g} \mathrm{Cr}$.

\section{Data analysis}

Differences between groups of subjects were assessed by an unpaired $t$-test, whereas within-group associations were assessed by the Pearson product-moment correlation method. Comparisons between frequencies were made by the homogenicity Chi-square test. Statistical significance was set at $P<0.05$.

\section{Results}

\section{NTG prevalence in regions of Greece with and without a past history of endemic goiter}

In previously endemic goiter regions (Table 1), the total mean prevalence of goiter (total number of schoolchildren with goiter from all previously endemic goiter regions per total number of schoolchildren examined) among the schoolchildren examined was $12.5 \%$, ranging from 0.0 to $25.4 \%$ in different schools. The majority of goiters were classified into the Stage Ia (69.4\%), according to the PAHO criteria, whereas 25.2 and $5.4 \%$ of goiters were classified into Stages Ib and II respectively. Mean UIE (mean \pm S.D., $120.8 \pm 77.0 \mu \mathrm{g}$ iodine/g Cr) fluctuated between $43.5 \mu \mathrm{g}$ iodine $/ \mathrm{g} \mathrm{Cr}$ (Dafni, Evritania) and $167.0 \mu \mathrm{g}$ iodine/g Cr (Gra-Lygia, Crete). Interestingly, a high prevalence of NTG goiter (14.0 and $25.4 \%$ respectively) was found in regions with both low (Athamanio, Ioannina; $45 \pm 59 \mu \mathrm{g}$ iodine/g Cr) and high UIE (Gra-Lygia, Crete; $167 \pm 163 \mu$ g iodine/g Cr) (Fig. 1, Domains a and d).

In regions with no past history of endemic goiter (Table 1), $1.7 \%$ of the schoolchildren examined had goiter (ranging from 0.0 to $6.7 \%$ in different schools). The overwhelming majority of goiters were classified into Stage Ia $(85.8 \%)$ according to the PAHO criteria, whereas only 13.6 and $0.6 \%$ of goiters were classified into Stages Ib and II respectively. Mean UIE was $167 \pm 150 \mu \mathrm{g}$ iodine $/ \mathrm{g} \mathrm{Cr}$ and varied between $95 \mu \mathrm{g} / \mathrm{g}$ $\mathrm{Cr}$ (Ampelokipi, Athens) and $191 \mu \mathrm{g} / \mathrm{g} \mathrm{Cr}$ (Agia Paraskevi, a suburb of Athens). All six regions had low mean NTG goiter prevalence $(<10 \%)$ and normal UIE (> $50 \mu$ g iodine/g Cr) (Fig. 1, Domain c).

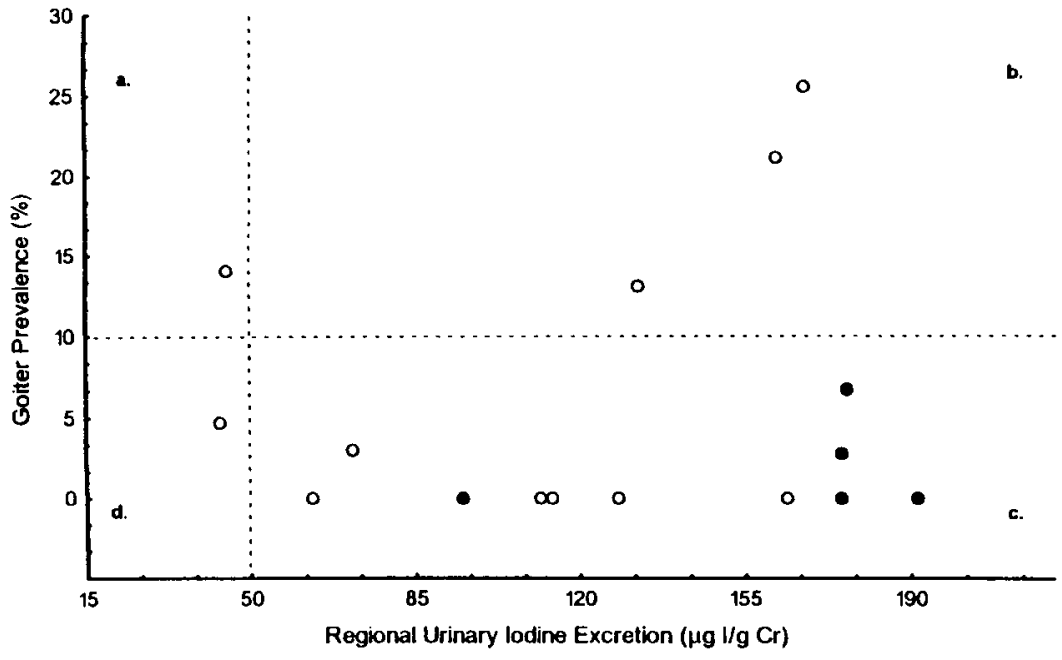

Figure 1 Mean goiter prevalence and mean UIE in studied areas in Greece with $(O)$ and without (๑) a past history of endemic goiter. Dashed lines indicate the $10 \%$ goiter prevalence (horizontal) and the $50 \mu \mathrm{g}$ iodine $/ \mathrm{g} \mathrm{Cr}$ UIE level (vertical), which represent the PAHO criteria for goiter endemia and iodine deficiency respectively. Domain a includes regions with high goiter prevalence and low UIE; Domain $b$ includes regions with both high goiter prevalence and UIE; Domain c includes regions with low goiter prevalence and high UIE; and Domain d includes regions with both low goiter prevalence and UIE. Two regions without a past history of endemic goiter (Agia Paraskevi and Syros) have the same goiter prevalence $(0 \%)$ and mean UIE (191 $\mu \mathrm{g}$ iodine/ $\mathrm{g} \mathrm{Cr}$ ), and are represented by the same solid circle. 
The mean prevalence of NTG goiter and mean UIE among the schoolchildren examined were significantly different between regions with and without a past history of endemic goiter $(P<0.05)$.

\section{The majority of NTG in Greek cities is autoimmune associated}

None of the patients included in this study had abnormal levels of $\mathrm{T}_{4}, \mathrm{RT}_{3} \mathrm{U}$ or $\mathrm{T}_{3}$. One hundred and twenty-seven out of 206 patients with NTG from Athens had ATG $(61.6 \%)$ while 79 patients had simple goiter $(38.4 \%)$ (Table 2). Goiter size, according to PAHO criteria, was classified mainly into Stages Ia and Ib, with few sporadic cases into Stage II or III. In Athens, ATG patients had significantly larger goiters than simple goiter patients; however, this was not found in Heraklion. The goiter size was similar between these groups of patients in both Athens and Heraklion. From 94 patients with NTG in Heraklion, 55 had ATG $(58.5 \%)$ and 39 had simple goiter $(41.5 \%)$. Serum TSH levels were significantly higher $(P<0.01)$ in ATG than in simple goiter patients, in both Athens and Heraklion. Also, in Heraklion, serum $\mathrm{T}_{4}$ and $\mathrm{RT}_{3} \mathrm{U}$ values were significantly lower in ATG than in patients with simple goiter $(P<0.05)$. The mean UIE did not differ between the ATG (mean \pm s.D., $231 \pm 119 \mu \mathrm{g}$ iodine/g Cr) and simple goiter patients $(206 \pm 100 \mu \mathrm{g}$ iodine/g $\mathrm{Cr}$ ) in both Athens and Heraklion $(P=0.14)$. In Heraklion, ATG patients were found to consume larger quantities of iodine-rich food than the patients with simple goiter $(P<0.01)$. Clinically estimated goiter weight correlated positively with the iodine-rich food consumption $(r=0.51, P<0.05)$ in all NTG patients from Heraklion (Fig. 2). This correlation was stronger when evaluated only in the ATG group among these patients $(r=0.63, P<0.05)$.
The prevalence of ATG among patients with NTG from Athens did not differ from that in those from Heraklion. Significantly less ATG patients from Athens (40.2\%) had TSH serum levels higher than $4 \mathrm{mU} / \mathrm{l}$ as compared with those from Heraklion $(61.6 \%)(P<$ 0.05). All ATG patients with TSH lower than $4 \mathrm{mU} / \mathrm{l}$ presented with significantly smaller goiters than ATG patients with TSH higher than $4 \mathrm{mU} / \mathrm{l} \quad(P<0.05)$. TPOAb correlated positively with goiter weight only in NTG patients from Athens $(r=0.1, P<0.01)$.

\section{Increase of autoimmune thyroid pathology findings in FNA between 1985 and 1986 and between 1994 and 1995}

Nine hundred and seventy-five pathology specimens from FNAs performed in patients with NTG between 1985 and 1986 revealed benign pathologies of the thyroid gland (Table 3). Fifty-eight among those $(5.94 \%)$ showed cytological characteristics compatible with autoimmune lymphocytic thyroiditis, whereas between 1994 and 1995, 376 out of 2702 benign thyroid specimens (13.91\%), showed these pathology characteristics $(P<0.05)$.

\section{Discussion}

The three studies reported here show that in Greece: (i) nowadays the iodine intake is generally normal; (ii) endemic goiter foci still persist; and (iii) thyroid autoimmunity is now largely prevalent among NTG patients.

The mean UIE (120.8 $\mu$ g iodine/g $\mathrm{Cr}$ ) among children in regions with a past history of endemic goiter is at the higher limit of the iodine dietary allowance (70-120 $\mu \mathrm{g}$ iodine/day for children aged 1-10 years) (17) and close

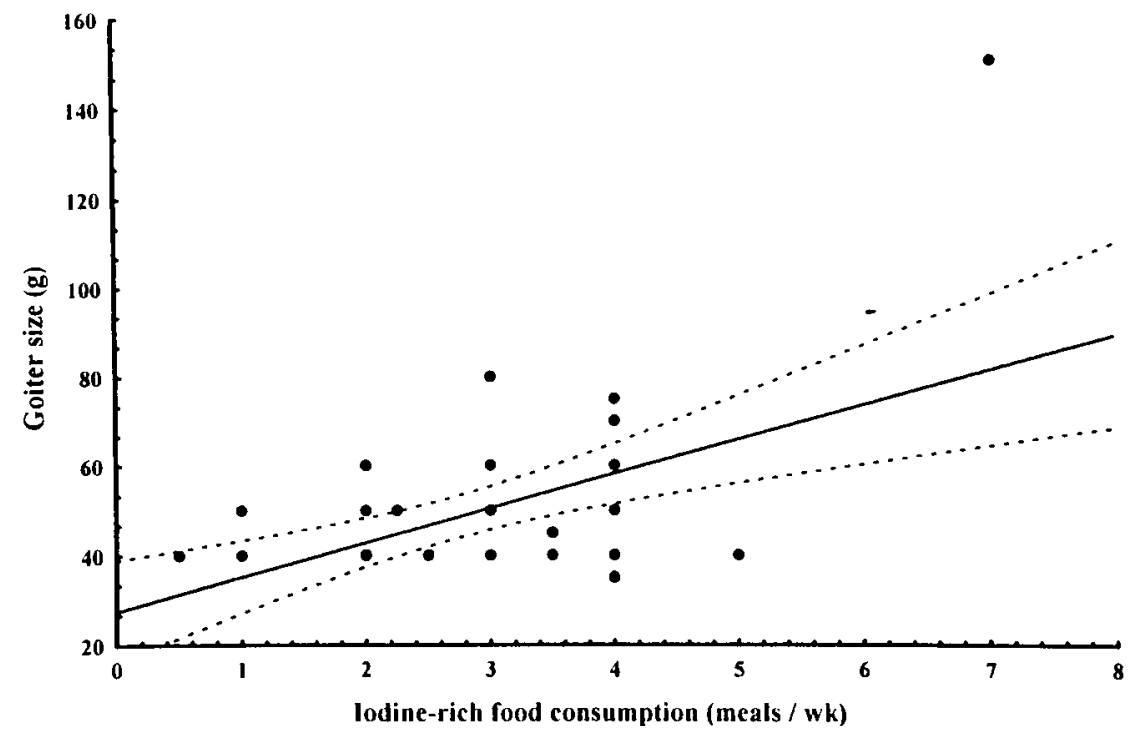

Figure 2 Positive correlation between goiter size and consumption of iodine-rich food (expressed as iodine-rich meals/ week) in the city of Heraklion, Greece $(r=0.51, P<0.05)$. Dashed lines indicate the $95 \%$ confidence limits. 
to the optimum value of $150-200 \mu \mathrm{g}$ iodine/g $\mathrm{Cr}$ as suggested by others (4). However, it is significantly lower than the mean UIE ( $166.8 \mu \mathrm{g}$ iodine $/ \mathrm{g} \mathrm{Cr})$ in the regions without a past history of endemic goiter. On the other hand, the mean prevalence of NTG among schoolchildren was significantly higher in regions with $(12.5 \%)$ than in regions without $(1.7 \%)$ a past history of endemic goiter. In only 4 out of 11 schools from the regions with a past history of endemic goiter was NTG prevalence higher than 10\% (Fig. 1, Domains a and d), the value defining goiter endemia according to the PAHO criteria $(11,12)$. However, absence of clinical goiter is not synonymous with normal thyroid since ultrasonographic studies in clinically normal schoolchildren have shown a small thyroid enlargement (18). Interestingly, in only one out of these four schools was the mean UIE less than $50 \mu$ g iodine/g Cr (Table 1; Fig. 1, Domain a), the value defining epidemiologically the lower limit for normal UIE $(11,12)$. Thus, it seems that goiter endemia persists only within well-defined 'foci' in the regions with a past history of endemic goiter in Greece even after iodine deficiency correction, suggesting the additional role of naturally occurring goitrogens such as Escherichia coli, which has been proven goitrogenic by producing thiouracil (19). In the past we have found an increased number of $E$. coli pathogens in drinking water from Greek regions with high goiter prevalence compared with regions with low or no goiter prevalence (20).

Two-thirds of the patients with NTG (186 from 300; $60.7 \%$ ) from Athens and Heraklion had positive serum thyroid AAB. Serum TSH levels were elevated in these patients, indicating subclinical hypothyroidism. Patients with ATG from Athens had also statistically significantly larger goiter weight than patients with simple goiter ( 48.4 vs $44.7 \mathrm{~g}, P<0.05$, Table 2$)$. However, this difference has a dubious clinical significance since the inaccuracy of goiter weight estimation by clinical examination is about $40 \%$ (21). The increase of ATG has also been confirmed by our pathology study, which revealed that the percentage of autoimmunity stigmata among FNA smears increased significantly between 1985 and 1986 and between 1994 and 1995 from 5.94 to $13.91 \%$ respectively $(P<0.05)$. FNA has a relatively high index of accuracy, sensitivity and specificity in the diagnosis of autoimmune thyroid disease $(22,23)$. It is helpful in the differentiation of Hashimoto's thyroiditis from thyroid neoplasms (24) and other forms of lymphocytic thyroiditis (focal or peritumoral ones) (25). The difference in the thyroid cancer incidence among NTG patients, observed between the two time periods (1985-1986 and 1994-1995, 22\% and 9.93\% respectively, Table 3), is probably a factitious one. It is probably due to a selection bias during the 1985-1986 period when FNA was not widely available and only thyroid nodules clinically suspect for malignancy were examined by FNA.
Is this high prevalence of ATG in Greece nowadays significantly higher than in the past? In the older studies, serum AAB were not routinely measured, and when measured the methods used were not as sensitive as the present RIAs. However, $60 \%$ of the prepubertal children examined in endemic goiter regions 30 years ago presented with NTG according to the same clinical criteria used in the current study (1), while AAB measured by the complement-fixation test were present in $12 \%$ of these patients (4). Nowadays, the mean NTG prevalence among schoolchildren examined in regions with a previous history of goiter endemia is only $12.5 \%$, and the prevalence of ATG among NTG patients, with the new RIA tests, is $60 \%$. The decrease of the NTG prevalence followed by the ATG increase may support the relative character in the increase of the latter.

In Greece, iodine supplementation of salt and water was initiated after field studies in the late $1960 \mathrm{~s}(1-3$, $26,27)$. Increased iodine intake has been implicated in fueling the thyroid autoimmune process in both humans (8-10) and experimental animals $(28,29)$, resulting in the development of either Hashimoto's thyroiditis or Graves' disease. Our study failed to reveal a difference in UIE between ATG and simple goiter patients, indicating that high normal iodine intake may be considered rather as a permissive factor in the development of ATG. In a previous study we reported that of 58 patients with simple goiter injected with iodized oil, only $50 \%$ developed AAB (8). With the administration of smaller iodine amounts an even smaller number of patients developed AAB (30).

In conclusion, autoimmune thyroiditis is the predominant form of NTG in Greece nowadays. It seems that, following an increased intake of iodine in Greece, iodine-deficiency goiter has decreased and thus ATG has relatively increased. However, it is possible that iodine intake may also contribute to this increase in autoimmunity.

\section{References}

1 Malamos B, Koutras DA, Kostamis P, Kralios AC, Rigopoulos G \& Zerefos N. Endemic goiter in Greece: Epidemiologic and genetic studies. Journal of Clinical Endocrinology and Metabolism 196626 688-695.

2 Malamos B, Koutras DA, Marketos SG, Rigopoulos GA, Yataganas $\mathrm{XA}$, Binopoulos D et al. Endemic goiter in Greece: An iodine balance study in the field. Journal of Clinical Endocrinology and Metabolism 196727 1372-1380.

3 Malamos B, Miras K, Koutras DA, Kostamis P, Binopoulos D, Zerefos $\mathrm{N}$ et al. Endemic goiter in Greece: metabolic studies. Journal of Clinical Endocrinology and Metabolism 196626 696704.

4 Moulopoulos DS, Koutras DA, Mantzos J, Souvatzoglou A, Piperingos GD, Karaiskos KS et al. The relation of serum $\mathrm{T}_{4}$ and TSH with the urinary iodine excretion. Journal of Endocrinological Investigation $198811437-439$.

5 Koutras DA, Katsouyanni K, Livadas DP, Piperingos GD, Tzonou A \& Trichopoulos D. An epidemiologic survey of thyroid enlargement among schoolchildren in a non-endemic area. Endokrinologie $198279349-354$. 
6 Koutras DA, Piperingos G, Mantzos J, Boukis M, Karaiskos KS \& Hadjiioannou S. Iodine nutrition and iodine deficiency disorders in Greece: Signs of improvement. In Iodine Deficiency in Europe. A Continuing Concern, pp 421-426. Eds F Delange, JT Dunn \& D Glinoer. New York: Plenum Press, 1993.

7 Koutras DA. Variation in incidence of goiter within iodine-deficient populations. In Endemic Goiter and Cretinism: Continuing Threats to World Health, pp 95-101. Eds JT Dunn \& G Medeiros-Neto. Washington DC: PAHO Science Publishers, 1974.

8 Boukis MA, Koutras DA, Souvatzoglou A, Evangelopoulou A, Vrontakis M \& Moulopoulos SD. Thyroid hormone and immunological studies in endemic goiter. Journal of Clinical Endocrinology and Metabolism 198357 859-862.

9 Harach HR \& Williams ED. Thyroid cancer and thyroiditis in the goitrous regions of Salta, Argentina, before and after iodine prophylaxis. Clinical Endocrinology 199543 701-706.

10 Kahaly GJ, Dienes HP, Beyer J \& Hommel G. Iodide induces thyroid autoimmunity in patients with endemic goitre: a randomised, double blind, placebo-controlled trial. European Journal of Endocrinology 1998139 290-297.

11 Querido A, Delange F, Dunn JT, Fierro-Benitez A, Ibbertson HK, Koutras DA et al. Definition of endemic goiter and cretinism, classification of goiter size and severity of endemias and survey techniques. In Endemic Goiter and Cretinism: Continuing Threats to World Health, p 267. Eds JT Dunn \& G Medeiros-Neto. Washington DC: PAHO Science Publishers, 1974.

12 Delange F, Bastani S, Benmiloud M, De Maeyer E, Isayama MG, Koutras D et al. Definitions of endemic goiter and cretinism, classification of goiter size and severity of endemias and survey techniques. In Towards the Eradication of Endemic Goiter, Cretinism, and Iodine Deficiency, pp 373-376. Eds JT Dunn, EA Pretell, C Hernan Daza \& FE Viteri. Washington DC: PAHO Science Publishers, 1986.

13 Koutras DA, Papapetrou PD, Yataganas X \& Malamos B. Dietary sources of iodine in areas with and without iodine-deficiency goiter. American Journal of Clinical Nutrition 1970 23 870-874.

14 Jarlov AE, Nygaard B, Hegedus L, Hartling SG \& Hansen JM. Observer variation in the clinical and laboratory evaluation of patients with thyroid dysfunction and goiter. Thyroid $1998 \mathbf{8}$ 393-398.

15 LiVolsi VA. The pathology of autoimmune thyroid disease. Thyroid 1994 $4333-339$.

16 Benotti J \& Benotti N. Protein-bound iodine, total iodine, and butanol-extractable iodine by partial automation. Clinical Chemistry $19639408-416$.

17 Food and Nutrition Board, US National Research Council, Committee on Dietary Allowances. Iodine: Recommended Dietary Allowances, edn 10, p 213. Washington DC: National Academy Press, 1989.
18 Papamichail MK. Clinical, biochemical and ultrasonographic studies of non-toxic goiters in Greece. Thesis. University of Athens, 1997

19 Reid GM \& Tervit H. Sudden infant death syndrome and placental disorders: the thyroid-selenium link. Medical Hypotheses 199748 317-324.

20 Malamos B, Koutras DA, Rigopoulos GA, Papapetrou GD, Gougas E, Kelperi $\mathrm{H}$ et al. Endemic goiter in Greece: some new epidemiologic studies. Journal of Clinical Endocrinology and Metabolism 197132 130-139.

21 Jarlov AE, Hegedus L, Gjorup T \& Hansen JEM. Accuracy of the clinical assessment of thyroid size. Danish Medical Bulletin 1991 38 87-89.

22 Konno N, Abe S, Uematsu T, Kanaya A \& Wakabayashi J. Evaluation of fine needle aspiration cytology in the diagnosis of thyroid diseases. Hokkaido Igaku Zasshi 198964 186-194.

23 Ribeiro CA \& Brasileiro Filho G. Histocytological correlation in fine needle aspiration biopsy of the thyroid gland. Revista da Associacao Medica Brasileira 199642 73-78.

24 Ravinsky E \& Safneck JR. Differentiation of Hashimoto's thyroiditis from thyroid neoplasms in fine needle aspirates. Acta Cytologica $198832854-861$.

25 Tseleni-Balafouta S, Kyroudi-Voulgari A, Paizi-Biza P \& Papacharalampous NX. Lymphocytic thyroiditis in fine needle aspirates: differential diagnostic aspects. Diagnostic Cytopathology 19895 362-365.

26 Koutras DA, Papadopoulos SN, Sfontouris J, Rigopoulos GA, Pharmakiotis AD \& Malamos B. Endemic goiter in Greece: Clinical and metabolic effects of iodized salt. Journal of Clinical Endocrinology and Metabolism 196828 1651-1656.

27 Malamos B, Koutras DA, Mantzos J, Chiotaki L, Sfontouris J, Papadopoulos SN et al. Endemic goiter in Greece: effects of iodized oil injection. Metabolism 197019 569-580.

28 Bagchi N, Brown TR, Urdanivia E \& Sundick RS. 1985 Induction of autoimmune thyroiditis in chickens by dietary iodine. Science $1985230325-327$.

29 Sundick RS, Herdegen DM, Brown TR \& Bagchi N. The incorporation of dietary iodine into thyroglobulin increases its immunogenicity. Endocrinology $19871202078-2084$.

30 Koutras DA, Piperingos GD, Pallas D, Katsouyanni K, Karaiskos KS, Marafelia P et al. Clinical, laboratory and immunologic effects of the treatment of endemic goiter with $\mathrm{T}_{4}, \mathrm{~T}_{3}$ and KI. Thyroidology 19902 81-88.

Received 8 January 1999

Accepted 8 March 1999 